\title{
Synthesis of Highly Active Ruthenium Sulfide Hydrodesulfurization Catalysts: Effect of Hydrogen in the Activation Process
}

\author{
C. Ornelas ${ }^{1}$, R. Farias ${ }^{2}$, A. Aguilar-Elguézabal ${ }^{1}$ and L. Alvarez-Contreras ${ }^{1}$
}

${ }^{1}$ Centro de Investigación en Materiales Avanzados (CIMAV), Laboratorio Nacional de Nanotecnología, Miguel de Cervantes No.120, C.P. 31109, Chihuahua, Chih., México.

${ }^{2}$ Institute of Engineering and Technology, Autonomous University of Juarez, UACJ, Ave. del Charro \#610 norte, C.P. 32320, Cd. Juárez, Chihuahua, México.

In 1981 Pecoraro and Chianelli reported a complete study of catalytic behavior of transition metal sulfides catalysts in hydrodesulfurization (HDS) of dibenzothiophene (DBT) [1], in which was found a periodic tendency of the metallic sulfides activity, where ruthenium sulfide showed the highest HDS activity. These results were corroborated later by Raje et al. [2] and Liaw et al. [3], further studies coincided with the high catalytic activity of the ruthenium sulfide [4] superior to molybdenum traditional catalyst. Despite of Pecoraro results, the recent studies reported for ruthenium sulfide catalysts barely have achieved activities similar to those of industrial catalyst and only a few have reached the activity reported by Pecoraro [5]. Many authors related the low ruthenium sulfide catalytic activity with low sulfuration levels and remaining of metallic ruthenium in the catalyst, associated with the use during the activation process of hydrogen which is a reduction agent $[6,7,8]$, nevertheless the role of metallic ruthenium in the HDS reaction is not clear.

Recently, our group using a new ruthenium precursor has synthesized a ruthenium sulfide catalyst with catalytic activity higher than industrial catalysts $[9,10]$, in this research work, the structure of the catalyst and the role of different amount of hydrogen in the activation process are evaluated. The catalysts were synthesized following the procedure used in previous work $[9,10]$ and were activated by $2 \mathrm{hr}$ in a tubular furnace at $673 \mathrm{~K}$ whit reduction atmosphere of $\mathrm{H}_{2} \mathrm{~S} / \mathrm{H}_{2}$ at $2,5,15 \%$ of $\mathrm{H}_{2} \mathrm{~S}$. The resulted catalysts were tested in the HDS of DBT reaction. The HDS studies were carried out in a Parr model 4560 high-pressure batch reactor. 0.25 gram of catalyst was placed in the reactor with a solution of 5 vol. \% of DBT in decaline. The reactor was pressurized to $3.1 \mathrm{MPa}$ with hydrogen and heated up until $623 \mathrm{~K}$. After the working temperature was reached, sampling for chromatographic analysis was performed during the course of each run to determine conversion versus time dependence.

The materials were characterized by different techniques to know the hydrogen effect in the activation process and ruthenium phase or structure obtained in the catalysts. The table 1 shows the catalytic activity; almost the same catalytic activity for alls catalysts is observed, in spite of very high hydrogen content in activation process for the catalyst $2 \%\left(98 \%\right.$ of $\left.\mathrm{H}_{2}\right)$. The $\mathrm{Z}$ contrast micrographs taken by a HRTEM JEOL JEM2200FS+Cs for 2\% catalyst (figure 1a)) show metallic ruthenium inside of the particles which are like core-Shell particles, this metallic structures were not found in 5\% (figure $1 \mathrm{~b}$ )) or $15 \%$ catalyst. Nevertheless, the core shell metallic ruthenium particles we found that hydrogen in the activation process are not the main factor to achieve good catalytic activity because the HDS active sites are in catalyst surface located in the shell of the structures. 
References:

[1] Pecoraro T. A. and Chianelli R. R., Journal of Catalysis, 67 Issue 2 (1981), 430-445.

[2] Raje A. P, et al, Applied Catalysis A: General 150 (1997), 297-318.

[3] Liaw S-J., et al, Applied Catalysis A: General 151 (1997), 423-435.

[4] Chianelli R. R., Berhault G., Torres B., Catalysis Today, 147, (2009) 275-286.

[5] Klimova T., Mendoza Vara P., Lee I. P., Catalysis Today, 150, (2010) 171-178.

[6] Navarro R., et al, 1999. Fuel Processing Technology, 61, pp. 73-88.

[7] Castillo-Villalon P., Ramirez J., Mauge F., 2008. Journal of Catalysis, 260, pp. 65-74.

[8] Blanchard J., et al, 2009. Catalysis Today, 147, pp. 255-259

[9] Ornelas Gutiérrez Carlos Elías, et al. Mexican patent MX/a/2011/013529

[10] Ornelas Gutiérrez Carlos Elías, et al. US Patent 13/444,411.

Table 1. Catalytic properties and surface area of ruthenium sulfide catalysts activated with $\mathrm{H}_{2} \mathrm{~S} / \mathrm{H}_{2}$ at different concentrations of $\mathrm{H}_{2} \mathrm{~S}$.

\begin{tabular}{|l|l|l|l|l|}
\hline \multirow{2}{*}{ Catalyst } & \multicolumn{2}{|l|}{ Surface Area $\left(\mathrm{m}^{2} / \mathrm{g}\right)$} & $\begin{array}{l}\text { Catalytic Activity } \\
\mathrm{K}\left(\mathrm{E}^{-06}\right)\end{array}$ & Selectivity \\
\cline { 2 - 5 } & AR & DR & Mol/seg*g & HYD/HDS \\
\hline $15 \%$ & 94.7 & 99.6 & 8.32 & 0.47 \\
\hline $5 \%$ & 41.3 & 41.3 & 8.01 & 0.41 \\
\hline $2 \%$ & 115.5 & 74.0 & 7.85 & 0.43 \\
\hline
\end{tabular}
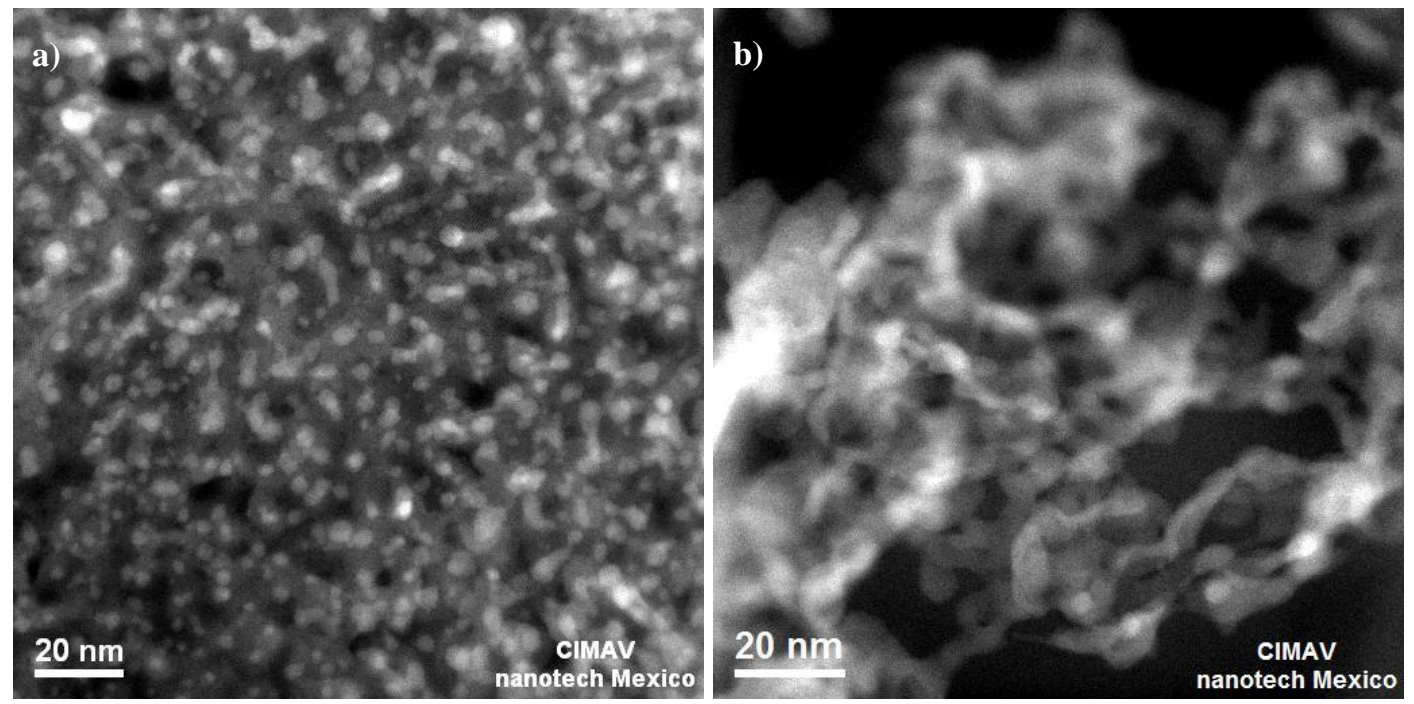

Figure 1. $\mathrm{Z}$ contrast micrographs by HRTEM of catalyst activated with a) $2 \%$ and b) $5 \%$ of $\mathrm{H}_{2} \mathrm{~S} / \mathrm{H}_{2}$. 